\title{
Towards a Module-based Product Platform for Ship Locks Using DSM Methods
}

\author{
S.C.M. Knippenberg ${ }^{1}$, L.F.P. Etman ${ }^{1}$, J.E. Rooda ${ }^{1}$, T. Wilschut ${ }^{2}$, J.A. Vogel $^{3}$ \\ ${ }^{1}$ Eindhoven University of Technology, $5600 \mathrm{MB}$, Eindhoven, The Netherlands \\ ${ }^{2}$ Ratio CASE B.V., 5617 AB, Eindhoven, The Netherlands \\ ${ }^{3}$ Rijkswaterstaat, 3526 LA, Utrecht, The Netherlands
}

\begin{abstract}
A significant number of ship locks in the Netherlands are due for renovation during the coming decades. To achieve this, Rijkswaterstaat (RWS), the executive branch of the Dutch Ministry of Infrastructure and Water Management, is investigating the options to meet the specific requirements, while allowing the necessary variety in the configuration of locks. This paper presents a method for the development of a module-based product platform for locks, based on component types and their combinations. By combining different design structure matrix (DSM) modeling methods, possible modules of lock components are defined and assessed. These modules consist of lock components that have a high level of commonality and thus influence each other. Together, these modules form the basis for a product platform for locks, supporting RWS with the renovation of their portfolio.
\end{abstract}

Keywords: Ship lock renovation, Product platform, Compatibility DSM, Coverage DSM, Modularization

\section{Introduction}

Ship locks are essential elements of the Dutch infrastructure as they facilitate waterborne transportation by regulating differences in water level between waterways. When a ship approaches a lock, the gate on one side of the lock opens and the ship can enter the lock chamber. Next, the gate is closed and the water level is raised or lowered towards the level on the other side of the lock. Finally, the gate on the other side of the lock opens and the ship can continue its way.

Responsible for the functioning of ship locks in the main waterways in the Netherlands is Rijkswaterstaat (RWS), which is the executive branch of the Dutch Ministry of Infrastructure and Water Management. By investigating their lock portfolio, RWS has concluded that a majority of locks reach the end of their predicted technical lifetime in the upcoming decades or do not meet modern-day standards. Besides, several locks do not have sufficient capacity to transfer ships, given the projected growth of waterborne transportation. These conclusions result in the planned renovation of a major part of the lock portfolio. To support this renovation, RWS has founded the MultiWaterWerk (MWW) project. The goal of this project is to accommodate the serial renovation process of locks by modularizing and (partially) standardizing lock components, to reduce life cycle costs and improve the maintainability of the lock portfolio.

Within the MWW project, Wilschut et al. (2019) analyzed the current lock portfolio and concluded that the prevalent lock realization strategy has been Engineer-to-Order. As a 
result, most locks in the Netherlands have a unique lock configuration to meet the needs, requirements, and constraints of a specific lock location. The work of Wilschut et al. is based on current configurations of ship locks in the Netherlands as input, which can be considered as brownfield process-related constraints (Lehtonen et al., 2011). However, the scope of the renovation of locks allows considering greenfield related constraints, to reassess existing preferences for lock design, and to investigate options to arrive at a product platform for ship locks. Meyer and Lehnerd (2011) define a product platform as a set of common components, modules, or parts that can be applied to effectively generate a stream of derivative products. Furthermore, Meyer and Lehnerd state that handling the increasing complexity of products can be assisted by developing product families and that these families might reduce the costs of product development.

For the development of product families of ship locks, two types of product family design can be distinguished (Du et al., 2014). The first one is scaled product family design, in which one or more dimensions of a product platform can be scaled to satisfy various applications of the platform (Simpson, 2004). The development of a scalable product platform for ship locks has been studied in Knippenberg et al. (2019), resulting in five basic lock configurations that can be used as a basis for a scalable product platform. The other product family design type is called module-based or configurational, whereby product variants can be configured by combining various modules (Ulrich, 1995). A module-based product platform might be an alternative to the scalable platform based on selected configurations, since the lock portfolio of RWS currently has a wide range of variety between the locks, as indicated by Wilschut et al. (2019).

To arrive at a module-based product platform, hereafter called product platform, for the renovation of the lock portfolio of RWS, greenfield process-related constraints have been investigated that allow for variety between ship locks. Therefore, this paper proposes a structured method for the development of a product platform for ship locks in the Netherlands, by applying dependency structure matrix (DSM) techniques (Eppinger and Browning, 2012). This method is discussed in the upcoming sections, based on a selected set of twelve main components of a ship lock and their dependencies in Section 2. Next, the component type choices that are considered for inclusion are identified and the allowed type combinations are presented (Section 3). For five selected lock instances, Section 4 determines the feasible component types, based on lock-specific determining parameters. In Section 5, the identification of (component) modules for the development of a product platform is elaborated and the results are discussed. Finally, conclusions about the method towards a product platform for the ship lock portfolio of RWS are presented in Section 6.

\section{Lock components}

To illustrate the method for the development of a product platform for locks, a selection of components has been used from the lock decomposition by Wilschut et al. (2019). Based on this work and the lock construction principles presented in Josephus Jitta (1947) and Glerum and Vrijburcht (2000), twelve components have been selected that are known to have a major influence on the system performance and on type choices for the other components. This selection corresponds to the components considered in our earlier work 
Knippenberg, S.C.M.; Etman, L.F.P.; Rooda, J.E.; Wilschut, T.; Vogel, J.A.

mentioned above (Knippenberg et al., 2019). An overview of the components and their function within a lock is given in Table 1.

Table 1: Twelve lock components with their function within a lock.

\begin{tabular}{|c|c|c|}
\hline ID & Component & Function \\
\hline 1 & Leading jetty & Guiding ships into the lock chamber. \\
\hline 2 & Leveling system & Leveling water inside the lock chamber. \\
\hline 3 & Gates & $\begin{array}{l}\text { Retaining water during water leveling when closed and } \\
\text { allowing ships to enter when open. }\end{array}$ \\
\hline 4 & Gate actuators & Facilitating the opening and closing of gates. \\
\hline 5 & Leveling system actuators & Facilitating the opening and closing of the leveling system. \\
\hline 6 & Lock head & $\begin{array}{l}\text { Providing support, turning points, and guides for gates and } \\
\text { gate actuators. }\end{array}$ \\
\hline 7 & Lock chamber & $\begin{array}{l}\text { Isolating a part of the waterway, in which ships can be } \\
\text { raised or lowered. }\end{array}$ \\
\hline 8 & Seepage screens & $\begin{array}{l}\text { Preventing construction instabilities, caused by water } \\
\text { flowing through the soil outside the lock. }\end{array}$ \\
\hline 9 & Ice prevention system & $\begin{array}{l}\text { Preventing ice to obstruct gates, leveling systems, actuators, } \\
\text { and passing ships. }\end{array}$ \\
\hline 10 & Soil protection & $\begin{array}{l}\text { Protecting the soil outside the lock for propeller turbulences } \\
\text { and for the outflow of water. }\end{array}$ \\
\hline 11 & $\begin{array}{l}\text { Salt/fresh water } \\
\text { separation system }\end{array}$ & $\begin{array}{l}\text { Separating fresh and salt water between the waterways } \\
\text { separated by a lock. }\end{array}$ \\
\hline 12 & $\begin{array}{l}\text { Supervisory control } \\
\text { system }\end{array}$ & $\begin{array}{l}\text { Controlling the components of a lock to ensure correct and } \\
\text { safe dynamic behavior. }\end{array}$ \\
\hline
\end{tabular}

The dependencies between the components of Table 1 are presented in the component DSM in Figure 1 and can represent a physical connection, an information flow, a material flow, and/or an energy flow. For example, a physical connection between the gates and the lock head or an information flow from the supervisory control system towards the gate actuators for opening or closing the gates. The DSM is based on the component DSM from Knippenberg et al. (2019), which has been updated incorporating new insights.

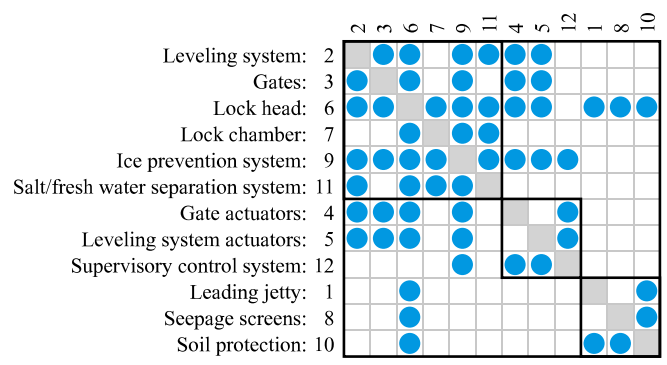

Figure 1: Component DSM of the twelve components, with three modules.

The DSM in Figure 1 contains twelve components, which have been grouped into three modules, based on their function within a lock. The modules correspond to the damming of water inside the lock (top-left), the actuation of components (middle), and the damming of water outside the lock (bottom-right). The dependencies between the components in this component DSM are used in the proposed method to arrive at a product platform for locks in the upcoming sections. 


\section{Feasible component type combinations}

To obtain insight into the configuration options for the lock portfolio of RWS, the feasibility of combining various component type choices has been determined for each of the twelve components. Each component choice is represented by a set of available component embodiments for the design of a lock. For example, the following five embodiments for the gates are considered, as shown in Figure 2.

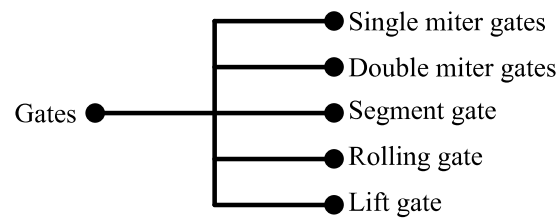

Figure 2: Five available component types for the gates of a lock.

The number of component types for each of the twelve components ranges from 2 to 36 . For the considered twelve components, a total of 105 component types are available. Around 9,000 different lock configurations can be generated combining the various type choices. In practice, this number of combinations is limited by physical restrictions, e.g. miter gates can never be opened or closed by lift gate actuators. To provide a structured overview of the feasible type combinations, a compatibility DSM has been generated (Hellenbrand and Lindemann, 2008). This DSM indicates the combinations of feasible type combinations. Figure 3 presents a schematic compatibility DSM to illustrate its principle. An entry in the matrix indicates the feasibility of combining that particular type choice of one component with the type choice of a component that has a dependency.

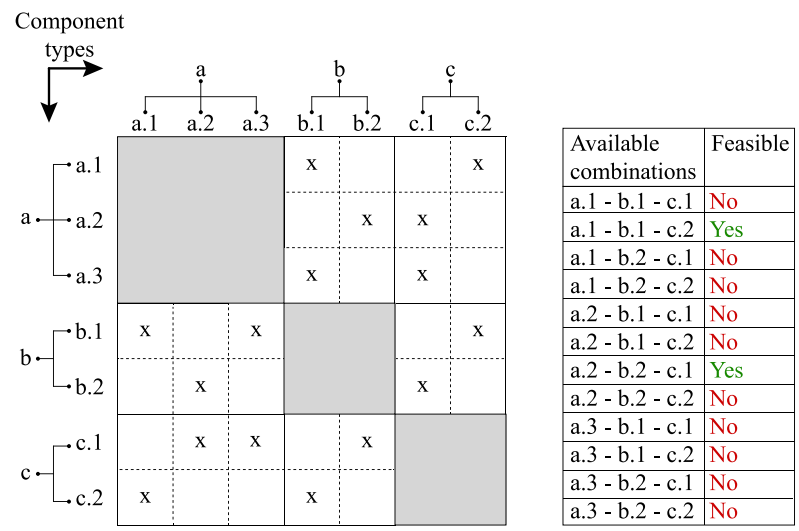

Figure 3: A schematic compatibility DSM to illustrate its working principle.

From the compatibility DSM in Figure 3, it has been derived that the feasible configurations are a. 1 - b. 1 - c. 2 and a. 2 - b. 2 - c. 1 . That is, component types a. 1 and b.1, a. 1 and c.2, and b. 1 and c. 2 can be combined in the first configuration, and a.2 and b.2, a.2 and c.1, and b.2 and c. 1 are allowed to combine in the second configuration. The other configurations are not feasible. 
The feasible configurations for the 105 component types of the twelve lock components are presented in the compatibility DSM of Figure 4. The grey blocks on the diagonal of the DSM represent the twelve lock components in an identical order as presented in Figure 1. The numbers indicated in the grey blocks correspond to Table 1 . The size of the blocks indicates the number of available types for a specific component.

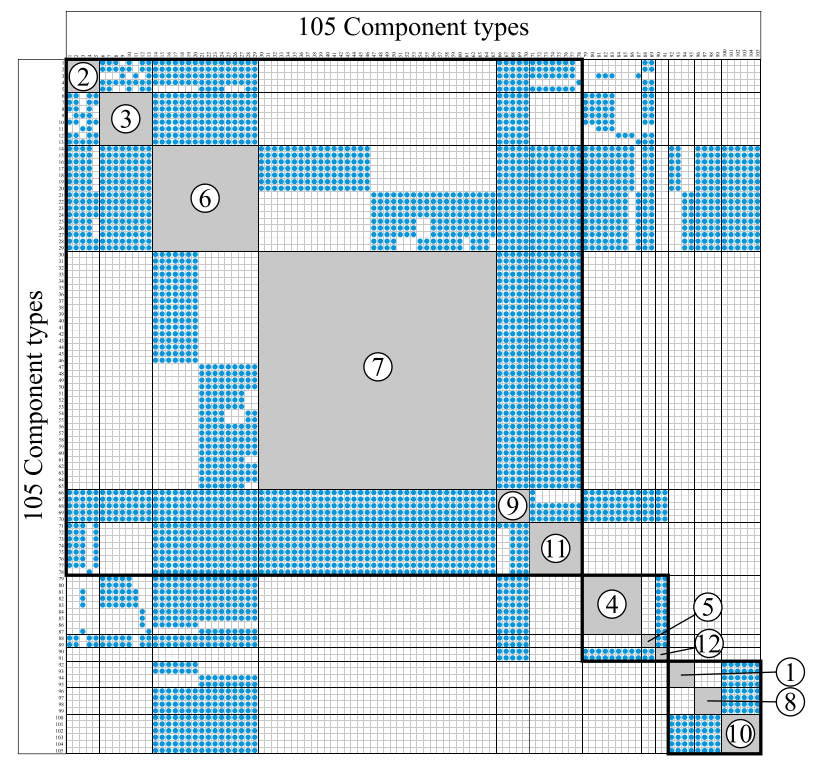

Figure 4: Compatibility DSM of the 105 component types with feasible type combinations in blue and with the twelve lock components in grey blocks.

The blue entries in the compatibility DSM of Figure 4 represent the set of feasible component type combinations to design a generic lock in the portfolio of RWS. The next step towards a product platform is to define which component types are allowed to be used in the design for specific locks in the portfolio.

\section{Allowed component types per lock instance}

The set of allowed component types for a specific lock follows from location-specific determining parameters. These parameters determine whether a particular component type is allowed for the design of the lock at that location. Examples of determining parameters include the waterway class, the water level difference, the required type of water retention, etcetera. The value ranges of determining parameters affecting component types have been gathered from Glerum and Vrijburcht (2000), RWS documentation of locks, and RWS expert interviews. Subsequently, the actual parameter values for the lock instances in the portfolio have been collected, to determine which of the component types are allowed. In Table 2, a snippet of the parameter to type choice mapping matrix is presented for the gate types (Figure 2) for five selected locks in the portfolio. The left part in this table (green) indicates the parameter value ranges that apply for certain gate types. The right part in Table 2 (blue) presents the actual values of these parameters for the five selected locks. 
Table 2: Some examples of determining parameters and their values, corresponding to the allowed gate types and the five selected locks.

\begin{tabular}{|c|c|c|c|c|c|c|c|c|c|c|}
\hline & 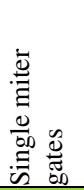 & 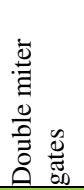 & 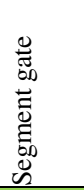 & 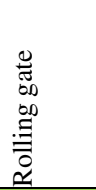 & 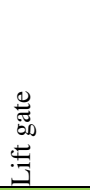 & 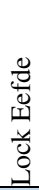 & 离 & 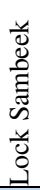 & 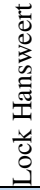 & $\frac{n}{4}$ \\
\hline $\begin{array}{l}\text { Waterway class } \\
\text { (CEMT) }\end{array}$ & I-VII & I-VII & I-VII & IV-VII & V-VII & V & VI & V & VI & II \\
\hline $\begin{array}{l}\text { Water retention } \\
\text { (Single [S]/ } \\
\text { Double [D]) }\end{array}$ & $S$ & D & S/D & S/D & S/D & $S$ & D & $\mathrm{S}$ & D & $S$ \\
\hline $\begin{array}{l}\text { Open/close } \\
\text { during water } \\
\text { flow }[\mathrm{Y} / \mathrm{N}]\end{array}$ & $\mathrm{N}$ & $\mathrm{N}$ & $\mathrm{Y} / \mathrm{N}$ & $\mathrm{N}$ & $\mathrm{Y} / \mathrm{N}$ & $\mathrm{Y}$ & $\mathrm{N}$ & $\mathrm{N}$ & $\mathrm{N}$ & $\mathrm{N}$ \\
\hline
\end{tabular}

By combining the green and blue matrices of Table 2, the allowed gate types for each of the five locks have been derived. When the value of a determining parameter value of a particular lock falls within the allowed parameter value range corresponding to a gate type choice, it implies that that specific gate type is allowed in the configuration of the specific lock instance. Figure 5 shows which gate types are allowed at the five selected lock instances. The figure indicates that for all five selected lock instances a segment gate can be chosen as gate type (third column full with entries).

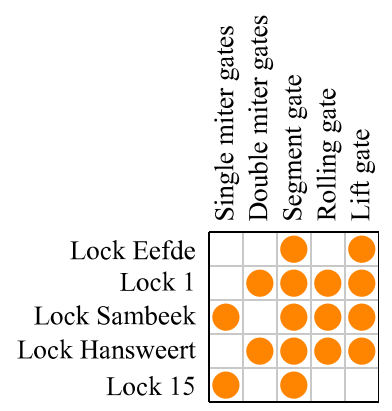

Figure 5: Five selected lock instances and allowed gate types, based on Table 2.

To determine the set of allowed component types per lock instance, the approach as described in this section is followed for each of the twelve lock components. In the upcoming section, the outcome of this approach is combined with the compatibility DSM of Figure 4.

\section{Assessing lock modules}

By combining the allowed component types (Section 4) and the compatibility DSM of Figure 4, compatibility DSM instances have been generated for each of the locks to assess possible lock modules. Each instance consists of only the set of allowed component types for that specific lock and thus consists of a subset of the compatibility DSM of Figure 4. 
An example of a compatibility DSM instance is presented in Figure 6, from which it can be observed that a major part of the component types has empty rows and columns. This observation indicates that the particular component types do not have to be considered when configuring the lock. Subsequently, it has been noticed that one of the components, marked with a red cross, has empty rows and columns. This implies that the respective component is not part of the lock instance and therefore, no type choice has to be made.

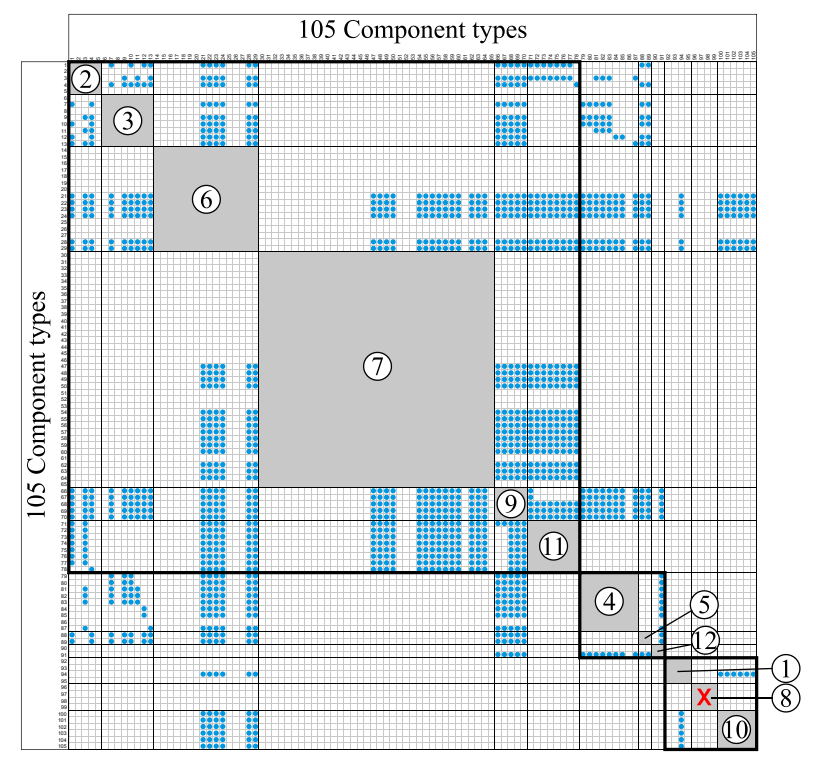

Figure 6: Compatibility DSM instance, consisting of the set of allowed component types.

To identify whether a particular type choice can be applied across multiple locks, that is, the commonality of component types regarding the lock architecture, a $\sum D S M$ is generated from the compatibility DSM instances of the five selected locks (Gorbea et al. 2008; Wilschut et al., 2019). In a EDSM, the sum of multiple DSMs is determined, as illustrated for the compatibility DSM instances in Figure 7. At entry $(i, j)$, the compatibility $\sum$ DSM denotes the number of times an $(i, j)$ entry occurs in the compatibility DSMs of the five locks. A higher value at entry $(i, j)$ in the compatibility $\sum$ DSM implies a higher commonality of the allowed combination of choice for component types $i$ and $j$.

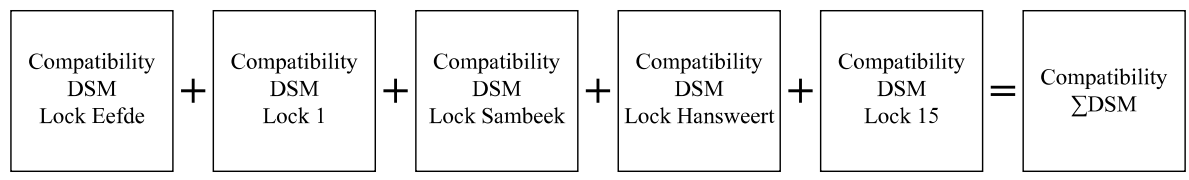

Figure 7: Compatibility $\sum$ DSM generation of the five locks.

The resulting compatibility $\sum$ DSM indicates the number of locks for which a combination of two component types $(i, j)$ is allowed. However, not all lock configurations consist of the same composition of lock components, as noticed in the compatibility DSM instance of 
Figure 6. To consider the differences in lock configurations, the coverage of component types and their combinations has been determined by dividing the number of type combinations in the compatibility $\sum$ DSM by the number of locks in which the corresponding component is part of. This coverage of component type combinations has been visualized in the coverage $\sum D S M$ of Figure 8 , in which the colors indicate the coverage of the type combinations that are present in the compatibility DSM instances. The coverages range from $20 \%$, implying that the type combination is allowed for only one of the five locks, to $100 \%$, implying that the type combination is allowed for all locks that have a configuration in which the specific components are present.

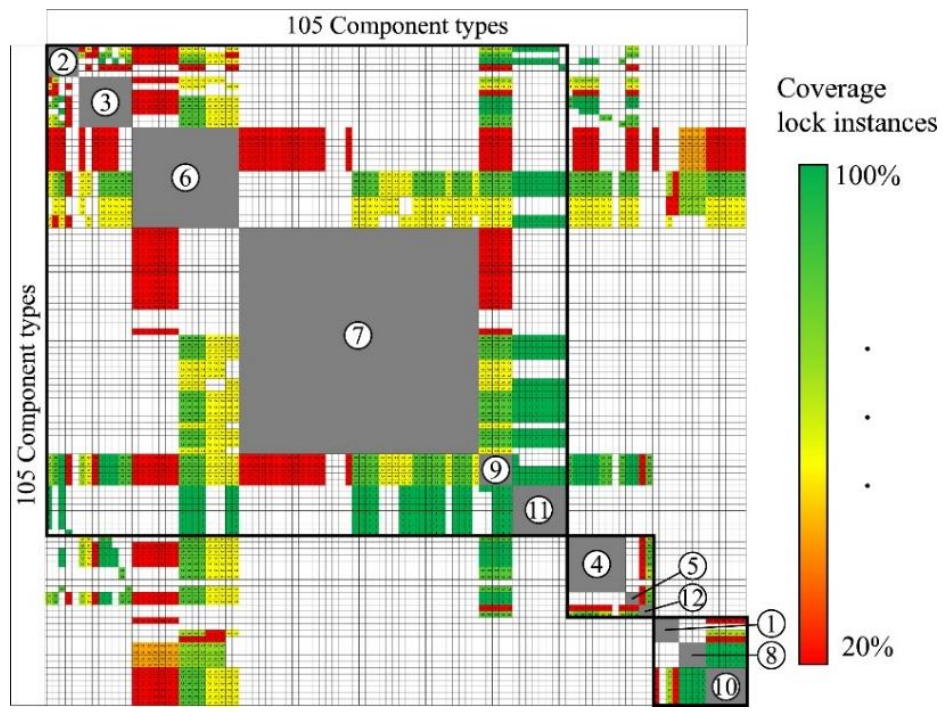

Figure 8: Coverage $\sum D S M$ of the five locks, indicating the coverage of type combinations.

The coverage $\sum$ DSM of Figure 8 shows the coverage of the component types and their combinations that are present in the compatibility DSM instances. It has been noticed that the type choices for lock head (third grey block, number 6), lock chamber (fourth grey block, number 7), and leading jetty (tenth grey block, number 1) are dependent since their combinations are comparably divided. Although this DSM contains the necessary information to assess the type choices and the formation of modules, collapsing this DSM display into a DSM that corresponds in size and layout to the component DSM of Figure 1 leads to a clearer and more accessible result. This collapsed DSM view has been achieved by combining the five compatibility DSM instances and the coverage DDSM.

Two possible variants of a collapsed coverage $\sum$ DSM are presented in Figure 9. The left DSM is based on the minimal required set of component types and their combinations for the configuration of the five locks, and the right DSM presents a variant with more freedom in type choices. The metrics that have been displayed in these DSMs are the number of types for each of the twelve components indicated along the diagonal, the number of feasible type combinations represented by the number of pie pieces in the matrix entry, and the coverage of each type combination expressed with different colors. 
Knippenberg, S.C.M.; Etman, L.F.P.; Rooda, J.E.; Wilschut, T.; Vogel, J.A.
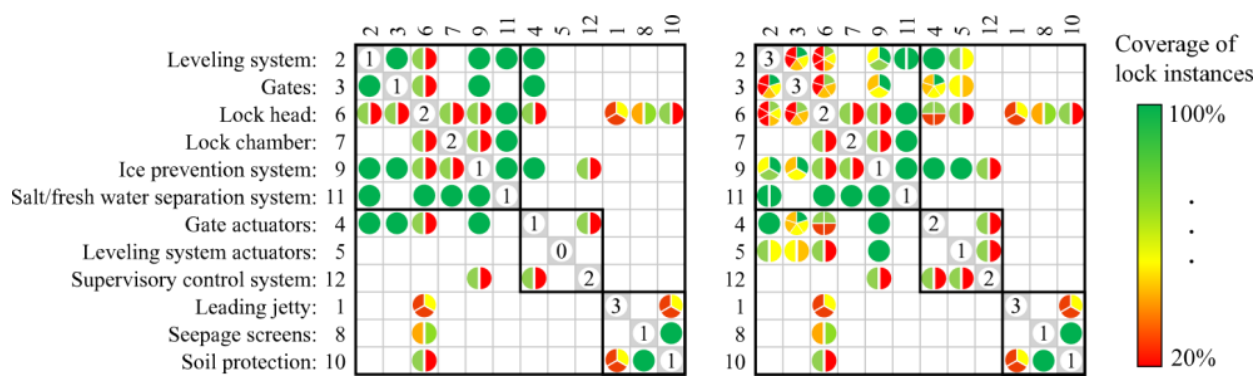

Figure 9: Collapsed coverage $\sum D$ DMs for the configuration of the five locks, with the minimal set of component types in the left DSM and a set with more freedom in type choice in the right DSM.

From the left DSM of Figure 9, it has been observed that the sum of parts for each of the pie charts equals $100 \%$, implying a minimal required set of component types and their combinations to configure the five locks. The top-left module in this DSM could be addressed as a candidate for standardization since the choices for lock head and lock chamber are mutually dependent (Figure 8) and therefore, only two variants of this module are required. In the middle module, it has been noticed that no leveling system actuator is required. This follows from the specific type choice for the leveling system that regulates differences in water level by opening the gates using the gate actuators. This module also requires two variants, due to the two types of the supervisory control system. Subsequently, the interfaces between the top-left and middle modules are mostly single pies of green color, which implies one standard interface serves almost all module choices. The bottomright module requires three variants for the configuration of the five locks, with multiple interfaces with the top-left module. However, the type choice for the leading jetty depends partially on the type choice for the lock head. So one may decide to let the choice for the third module be determined by the choice for the first module.

The right DSM of Figure 9 presents a set of component types for which more freedom in type choice has been granted. More types of leveling system, gates, gate actuators, and leveling actuators have been included. As a result, the percentages associated with the pies in the pie chart of an interface may add up to a value larger than $100 \%$. Due to this freedom, the number of allowed lock configurations has increased. Nevertheless, different lock configurations might have to reckon with different interfaces between modules.

\section{Conclusions}

Prior work by Wilschut et al. (2019) analyzed the current lock portfolio of Rijkswaterstaat. They concluded that the prevailing lock realization strategy resulted in a portfolio with most locks having a unique configuration. To support the planned renovation of a major part of the portfolio in the upcoming decades, a structured way of working is desired. This paper proposes such a method for the development of a module-based product platform for ship locks, using DSM techniques. The proposed method has been elaborated for five locks in the portfolio of RWS, and for twelve lock components that are main determinants for civil-mechanic lock design. Based on the selection of locks and the allowed components types, possible (component) modules of a product platform are assessed. 
The proposed method combines several DSM techniques to support the design of a product platform. First, dependencies between the selected lock components have been presented in a grouped component DSM. To indicate the allowed combinations of types for these components, a compatibility DSM has been created for a generic lock in the portfolio. Next, five locks have been selected from the portfolio of RWS, for which instances of the compatibility DSM have been generated. These compatibility DSM instances present allowed combinations of component types for the specific lock instance, based on determining parameters. The compatibility DSM instances are used to derive a LDSM to indicate the commonality of a combination of component types for the lock instances. The results of this $\sum D S M$ have been used to assess possible modules and their interfaces for the development of a product platform.

To illustrate the proposed method, a representative subset of the full decomposition of a lock has been used. Furthermore, only five locks from the portfolio have been used to build the DSMs. Future work seeks to cover the entire lock portfolio and an extended list of lock components in an effort to support the development of a product platform that can be used for the planned renovation of the RWS lock portfolio.

\section{Acknowledgments}

We thank Rijkswaterstaat, part of the Dutch Ministry of Infrastructure and Water Management, for supporting this research. In particular, we thank Maria Angenent, ErikJan Houwing, Patrizia Bernardini, and Robert de Roos for their enthusiastic involvement.

\section{References}

Du, G., Jiao, R.J., Chen, M., 2014. Joint optimization of product family configuration and scaling design by Stackelberg game. European Journal of Operational Research 232 (2014) 330-341.

Eppinger, S.D., Browning, T.R., 2012. Design structure matrix methods and applications. The MIT Press, Cambridge, MA.

Glerum, A., Vrijburcht, A., 2000. Design of locks. Bouwdienst Rijkswaterstaat, Utrecht, The Netherlands.

Gorbea, C., Spielmannleitner, T., Lindemann, U., Fricke, E., 2008. Analysis of hybrid vehicle architectures using multiple domain matrices. Proceedings of the 10th International DSM Conference (DSM 2008), Stockholm, Sweden, 11-12 November 2008, pp. 375-387.

Hellenbrand, D., Lindemann, U, 2008. Using the DSM to support the selection of product concepts. Proceedings of the 10th International DSM Conference (DSM 2008), Stockholm, Sweden, 11-12 November 2008, pp. 363-374.

Josephus Jitta, J.P., 1947. Sluizen en andere waterbouwkundige kunstwerken in en langs kanalen. De Erven F. Bohn N.V., Haarlem, The Netherlands. In Dutch.

Knippenberg, S.C.M., Etman, L.F.P., Rooda, J.E., Houwing, E.J., Vogel, J.A., 2019. Development of a product platform for ship locks using DSM methods. Proceedings of the 21st International DSM Conference (DSM 2019), Monterey, CA, 23-25 September 2019, pp. 153-163.

Lehtonen, T., Pakkanen, J., Järvenpää, J., Lanz, M., Tuokko, R., 2011. Brownfield process for developing of product families. Proceedings of the 2011 International Conference on Engineering Design (ICED11), 15-18 August 2011, Copenhagen, Denmark, pp. 248-257.

Simpson, T. W. (2004). Product platform design and customization: Status and promise. AIEDAM, 18(1), 3-20.

Wilschut, T., Etman, L.F.P., Rooda, J.E., Vogel, J.A., 2019. Similarity, modularity, and commonality analysis of navigation locks in the Netherlands. Journal of Infrastructure Systems, 25(1): 04018043.

Ulrich, K. (1995). The role of product architecture in the manufacturing firm. Research Policy, 24(3), 419-440.

Contact: S.C.M. Knippenberg, Eindhoven University of Technology, Department of Mechanical Engineering, PO Box 513, 5600 MB Eindhoven, The Netherlands, s.c.m.knippenberg@tue.nl 